\title{
Efficacy of Nepafenac versus Flurbiprofen in Maintaining Intraoperative Mydriasis During Phacoemulsification: A Comparative Study
}

This article was published in the following Dove Press journal: Clinical Ophthalmology

\section{Ankur K Shrivastava $\mathbb{D}$ \\ Swatishree Nayak \\ Mary Anto}

Department of Ophthalmology, All India Institute of Medical Sciences, Raipur, India
Purpose: To compare the efficacy of topical nepafenac $(0.1 \%)$ with flurbiprofen $(0.03 \%)$ in maintaining intra-operative mydriasis during phacoemulsification surgery.

Patients and Methods: This study comprised of 160 patients, who were divided into two arms of 80 each (arms A and B) after randomisation. Pre-operatively, all patients received one drop of tropicamide $0.8 \%$ and phenylephrine $5 \%$ (combination), 4 times, at an interval of 15 minutes on the day of surgery. Thereafter, Nepafenac drop in arm A/Flurbiprofen drop in arm B was administered 4 times, at an interval of 15 minutes keeping a gap of 10 minutes between tropicamide-phenylephrine and any of the experimental drugs. Phacoemulsification was performed one hour after the administration of last drop. Both vertical and horizontal pupillary diameter were measured at three steps; immediately before the surgical incision (baseline), at the end of emulsification of nucleus (before irrigation and aspiration) and at the end of surgery (after stromal hydration).

Results: The difference in pupillary diameter between two groups, was statistically insignificant for vertical diameter $(\mathrm{P}=0.08)$ and horizontal diameter $(\mathrm{P}=0.28)$ at the start of surgery. On the other hand, pupillary diameter difference was statistically significant after emulsification of nucleus and at the end of surgery as well when both vertical $(\mathrm{P}<0.05)$ and horizontal diameter $(\mathrm{P}<0.05)$ were considered. The total reduction in pupillary diameter (both vertically and horizontally) was significantly less in the Nepafenac as compared to Flurbiprofen group $(\mathrm{P}<0.05)$. Analysis of mean cumulative dissipated energy did not document any appreciable difference between the two groups. Phacoemulsification time analysis yielded statistically significant results $(P=0.004)$ between the Nepafenac and Flurbiprofen group.

Conclusion: In the present study, topical Nepafenac $(0.1 \%)$ proved to be more efficacious in maintaining intra-operative mydriasis during phacoemulsification surgery as compared to topical Flurbiprofen $(0.03 \%)$.

Keywords: topical nepafenac, topical flurbiprofen, intra-operative mydriasis, phacoemulsification

\section{Introduction}

Cataracts remain the principal cause of blindness and an imperative cause of visual impairment across the world. Phacoemulsification with in-the-bag implantation of intraocular lens has become the preferred surgical procedure as it offers the best visual results and faster rehabilitation. ${ }^{1-3}$ With time, cataract surgery has evolved into a relatively pain free, outpatient procedure owing to modern surgical techniques, advanced instrumentation and novel pharmaceutical therapeutics. Safe phacoemulsification mandates adequate
Correspondence: Ankur K Shrivastava Flat No. 603, Type 5A, AllMS Residential Complex, Kabir Nagar, Raipur, Chhattisgarh, 492099, India

Email shrivastavadrankur@gmail.com 
intraoperative mydriasis throughout the procedure. This improves visibility of structures present in the posterior chamber thus resulting in reduced surgical time and increased ease of surgery. A study by Guzek et al revealed that there is a fifty percent reduction in incidence of posterior capsule rupture if pupillary diameter is maintained above $6 \mathrm{~mm}$ throughout the surgery and each $1 \mathrm{~mm}$ reduction in pupil size doubles the risk of complications. ${ }^{4}$ Also, intraoperative miosis $(<6 \mathrm{~mm})$ results in an increase in other complications such as lens decentration, retained lens fragments, postoperative inflammation and vitreous loss. ${ }^{4-9}$

Topical cholinergic antagonists such as tropicamide along with adrenergic agonists such as phenylephrine have traditionally been used for the preoperative dilation of the pupil. In spite of adequate dilation, there is a subsequent onset of miosis after entry into the anterior chamber. ${ }^{10}$ Surgical trauma to the anterior chamber structures during cataract surgery leads to a breakdown of blood aqueous barrier and the release of prostaglandins leading to intraoperative miosis. Elevated levels of prostaglandins in the aqueous humor has been observed after routine cataract surgery and also reported after iris stroking. ${ }^{11,12}$ Non-steroidal anti-inflammatory drugs (NSAIDs) reduce the severity and incidence of intraoperative miosis by preventing prostaglandin synthesis via cyclooxygenase inhibition. ${ }^{13,14}$ Topical administration of various NSAIDs preoperatively has long been used for maintenance of intraoperative mydriasis. While intracameral mydriatics are gradually replacing topical formulations in countries with limited resources, topical agents are still a better choice, especially in high volume centres where trainee surgeons perform the major bulk of cataract surgery. With this rationale, the current study was carried out to compare the efficacy of topical Nepafenac $(0.1 \%)$ with Flurbiprofen $(0.03 \%)$ in maintaining intra-operative mydriasis during phacoemulsification surgery.

\section{Methods}

\section{Trial Registration}

The trial is registered at ClinicalTrials.gov, number: CTRI/ 2018/01/011277.

\section{Study Design}

This prospective, randomized, double-blinded, parallel group, comparative study with an allocation ratio of 1:1 was conducted at All India Institute of Medical Sciences, Raipur, India. Recruitment of patients was done from the 12th January 2018 to 11th January 2019. The study protocol was approved by the Institute Ethics Committee (approval number - 323/IEC-AIIMSRPR/2017) and the tenets of declaration of Helsinki were strictly adhered to throughout the study. Written informed consent was obtained from each participant. The study met the Consolidated Standards of Reporting Trials (CONSORT) guidelines. ${ }^{15}$

\section{Participants}

Out of one hundred and seventy patients assessed, one hundred and sixty eligible patients were enrolled. Patients forty years of age and above, diagnosed with cataract grade nuclear opalescence (NO) and/or nuclear color (NC) 2-3 \{according to Lens Opacities Classification System (LOCS) III $\}$ scheduled for cataract extraction by phacoemulsification were included in the study. The exclusion criteria were pregnant and lactating mothers; systemic diseases like diabetes mellitus, hypertension; ocular co-morbidities like pseudo-exfoliation, uveitis, local pupillary abnormalities, less than $6.00 \mathrm{~mm}$ pupil size prior to surgery, any previous intraocular surgery or trauma, intra-operative surgical complications like posterior capsular tear, vitreous loss, nucleus drop and zonular dehiscence. Patients with a history of systemic medications like NSAIDs or steroids in the past four weeks, alpha 1 receptor blockers, tricyclic antidepressants; topical ocular medications (except artificial teardrops) in past three weeks; with known allergy or hypersensitivity to preservatives, steroids, topical NSAIDs or any other component of study medications were also excluded from the study.

\section{Randomisation}

This study comprised of 160 patients, who were divided into two arms of 80 each (arms A and B) after randomisation using the online random number generator of Graph Pad (Prism 7). Patients in arm A received Nepafenac $(0.1 \%)$ while those in arm B received Flurbiprofen $(0.03 \%)$ eye drops, which was provided after removing labels, wrapping them with white paper and coding them as A and B. A designated resident who was not involved in the study was assigned the work of enrolling participants and putting eye drops.

\section{Blinding}

The operating surgeon and the patients undergoing surgery were unaware of the type of drug administered. 


\section{Sample Size Calculation}

Sample size was calculated by taking the confidence interval (CI) as $95 \%$ and power as $80 \%$. The difference of means was assumed as $0.5 \mathrm{~mm}$. The standard deviation (SD) for Nepafenac and Flurbiprofen were taken from earlier studies as $1.01 \mathrm{~mm}$ and $1.1 \mathrm{~mm}$ respectively. ${ }^{16}$ Using the appropriate formula, the sample size for the study was found to be 75 in each group. Considering drop out to be $5 \%, 80$ subjects were recruited in each group.

\section{Intervention}

A thorough ophthalmic examination including bestcorrected visual acuity (BCVA) using Snellen's chart, anterior segment evaluation by slit lamp bio-microscopy, intraocular pressure measurement by Goldmann applanation tonometry, dilated fundus examination by indirect ophthalmoscopy and grading of cataract according to LOCS III was done for all subjects included in the study. Medical, surgical history and use of any current medications were extensively reviewed.

Pre-operatively, all patients received one drop of tropicamide $0.8 \%$ and phenylephrine $5 \%$ (combination), 4 times, at an interval of 15 minutes on the day of surgery. Thereafter, Nepafenac drop in arm A/Flurbiprofen drop in arm B was administered 4 times, at an interval of 15 minutes keeping a gap of 10 minutes between tropicamide-phenylephrine and any of the experimental drugs. Surgery was performed one hour after the administration of last drop.

Clear corneal phacoemulsification was done in all cases by a single surgeon, under peribulbar anaesthesia with lignocaine $(2 \%)$, sodium hyaluronidase (1500 IU) and bupivacaine $(0.5 \%)$. The surgical technique as well as phacoemulsification parameters remained the same in every case. Both vertical and horizontal pupillary diameter were measured by placing Castroviejo's calliper in front of the cornea at three steps; immediately before the surgical incision (baseline), at the end of emulsification of nucleus (before irrigation and aspiration) and at the end of surgery (after stromal hydration). Intracameral use of adrenaline or pilocarpine was not done in any of the cases. Single microscope (Opmi Lumera 700, Carl Zeiss, Germany) with same settings of $26 \%$ illumination and $4.8 x$ magnification was used in all cases to ensure standardization during pupillary diameter measurement. Any adverse drug reactions after the instillation of topical NSAIDs were monitored.

\section{Outcomes}

The primary outcome ie, the difference in pupillary diameter between two groups were analysed at three steps, immediately before the surgical incision (baseline), after emulsification of nucleus (before irrigation and aspiration) and at the end of surgery (after stromal hydration). The percentage reduction in pupillary diameter from starting till end of surgery was also calculated in two groups. As secondary outcomes, total phacoemulsification time and cumulative dissipated energy (CDE) were also recorded for all cases.

\section{Statistical Methods}

Demographic characteristics and pupillary diameter measurement values were described as percentage, mean and standard deviation. Chi-square test was used for analysing categorical variables and unpaired two tailed $t$-test was used for continuous variables. A P value of less than 0.05 was considered statistically significant. All analysis was performed using SPSS software (version 24.0, IBM Corp., Armonk, New York).

\section{Results}

\section{Basic Information}

One hundred and seventy patients were assessed for eligibility. Ten cases were excluded ( 3 diabetic, 2 with pseudo exfoliation, 3 with uveitis and 2 with a history of systemic alpha 1 receptor blocker use) and the remaining 160 patients were recruited in the study $(41.25 \%$ males and 58.75\% females). Eighty patients were allocated to the Nepafenac and 80 to the Flurbiprofen group after randomization (Figure 1). The demographic characteristic of patients in each group is depicted in Table 1. There was no significant difference in age, gender and laterality of eye between the two groups.

\section{Intra-Operative Mydriasis}

The vertical and horizontal pupillary diameter at different stages of surgery is illustrated in Tables 2 and 3 respectively. The difference in pupillary diameter between the two groups, was statistically insignificant for vertical diameter $\{\mathrm{t}(158)=2.03, \mathrm{P}=0.08\}$ and horizontal diameter $\{\mathrm{t}$ $(158)=1.48, \mathrm{P}=0.28\}$ at the start of surgery. On the other hand, pupillary diameter difference was statistically significant after emulsification of the nucleus, when both vertical $\{\mathrm{t}(158)=10.07, \mathrm{P}<0.05\}$ and horizontal diameter $\{\mathrm{t}(158)=9.45, \mathrm{P}<0.05\}$ were considered. A significant difference was noted in the pupillary diameter between the two groups, both vertically $\{\mathrm{t}(158)=$ 


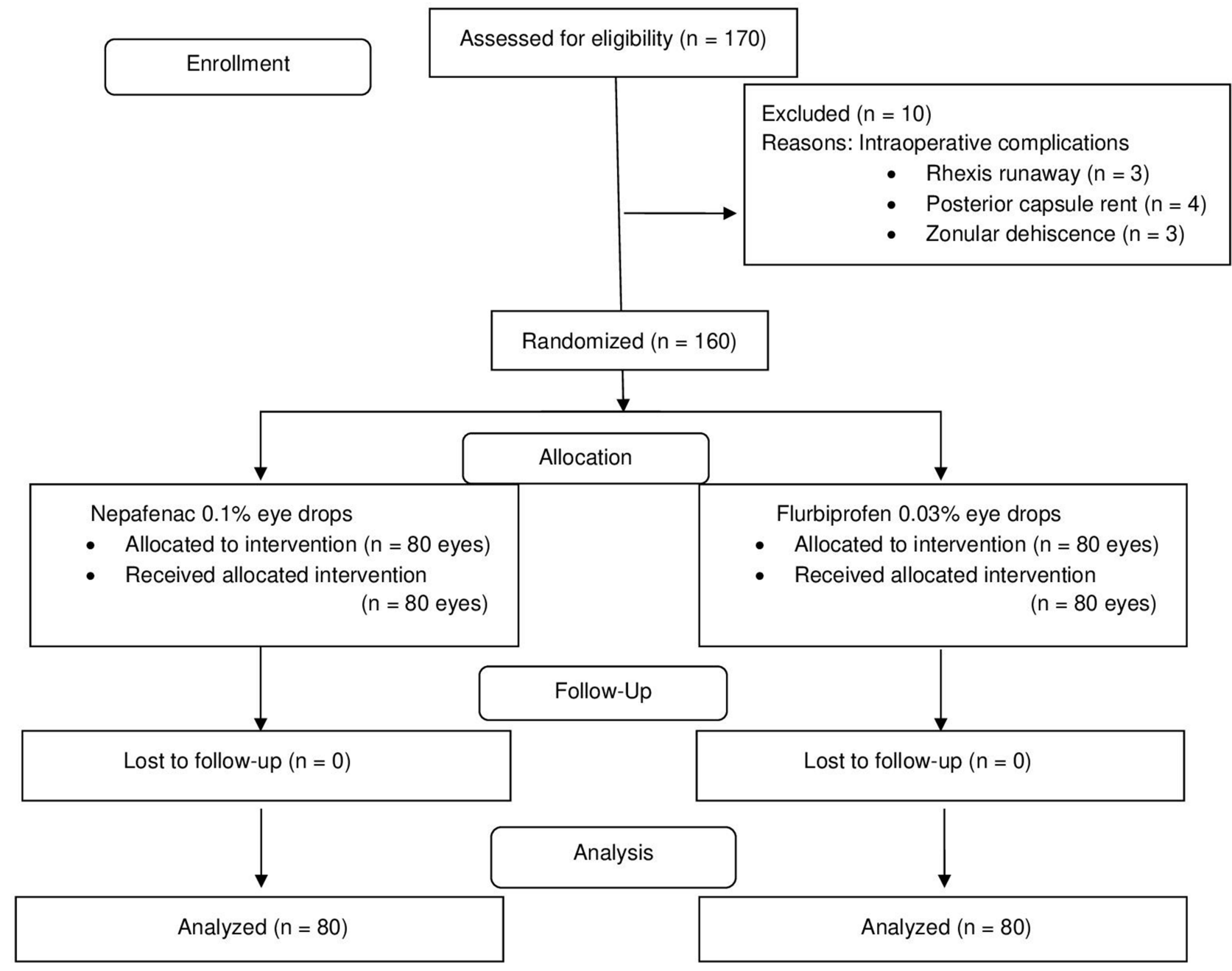

Figure I CONSORT flow diagram: efficacy of preoperative use of topical nepafenac versus flurbiprofen in the maintenance of intraoperative mydriasis during phacoemulsification.

$12.74, \mathrm{P}<0.05\}$ and horizontally $\{\mathrm{t}(158)=12.63, \mathrm{P}<$ $0.05\}$ at the end of surgery as well. Figure 2 shows sustained maintenance of intra-operative mydriasis for Nepafenac while Flurbiprofen showed a decrease in the

Table I Demographic Characteristics of Study Population

\begin{tabular}{|l|c|c|c|}
\hline Parameter & Nepafenac & Flurbiprofen & P value \\
\hline $\begin{array}{c}\text { Age (Years) } \\
\text { Mean } \pm \text { SD }\end{array}$ & $60 \pm 9.6$ & $59.21 \pm 7.50$ & 0.56 \\
\hline $\begin{array}{l}\text { Gender } \\
\text { Male }\end{array}$ & $35(43.75 \%)$ & $31(38.75 \%)$ & 0.52 \\
Female & $45(56.25 \%)$ & $49(61.25 \%)$ & \\
\hline $\begin{array}{l}\text { Laterality } \\
\text { Right }\end{array}$ & $41(51.25 \%)$ & $39(48.75 \%)$ & 0.75 \\
Left & $39(48.75 \%)$ & $41(51.25 \%)$ & \\
\hline
\end{tabular}

Abbreviation: SD, standard deviation. pupillary diameter with the progression of surgery. The total reduction in pupillary diameter (both vertically and horizontally) was significantly less in the Nepafenac as compared to the Flurbiprofen group $(\mathrm{P}<0.05)$.

\section{Phacoemulsification Parameters}

Analysis of mean CDE (Figure 3) did not document any appreciable difference between the two groups $(\mathrm{P}=0.772$, mean difference of $0.46,95 \%$ CI -0.58 to 1.5 ). Phacoemulsification time analysis (Figure 4) yielded statistically significant results $(\mathrm{P}=0.004$, mean difference of $-0.89,95 \%$ CI -1.45 to -0.32 ) between the Nepafenac and Flurbiprofen groups.

\section{Adverse Reactions}

No adverse drug reactions were documented in either group during the study. 
Table 2 Vertical Pupillary Diameter $(\mathrm{mm})$ at Different Stages of Surgery

\begin{tabular}{|l|c|c|c|c|}
\hline $\begin{array}{l}\text { Vertical Pupil Diameter } \mathbf{( m m )} \\
\text { Mean } \pm \text { SD }\end{array}$ & $\begin{array}{c}\text { Nepafenac } \\
(\mathbf{n}=\mathbf{8 0})\end{array}$ & $\begin{array}{c}\text { Flurbiprofen } \\
(\mathbf{n}=\mathbf{8 0})\end{array}$ & P value & MD (95\% Cl) \\
\hline At start of surgery & $8.60 \pm 0.44$ & $8.46 \pm 0.43$ & 0.08 & $0.14(0.005$ to 0.27$)$ \\
After emulsification of nucleus & $8.14 \pm 0.53$ & $7.16 \pm 0.69$ & $<0.05 *$ & $0.98(0.79$ to 1.17$)$ \\
At end of surgery & $7.71 \pm 0.54$ & $6.45 \pm 0.70$ & $<0.05 *$ & $1.26(1.07$ to -1.45$)$ \\
Total reduction in pupillary diameter & $0.89 \pm 0.49$ & $2.01 \pm 0.61$ & $<0.05 *$ & $-1.12(-1.29$ to 0.95$)$ \\
Percentage total loss & 10.34 & 23.75 & $<0.05 *$ & - \\
\hline
\end{tabular}

Note: $\mathrm{P}<0.05$ considered statistically significant*.

Abbreviations: $\mathrm{Cl}$, confidence interval; $\mathrm{MD}$, mean difference; $\mathrm{mm}$, millimetres; $\mathrm{SD}$, standard deviation.

Table 3 Horizontal Pupillary Diameter $(\mathrm{mm})$ at Different Stages of Surgery

\begin{tabular}{|l|c|c|c|c|}
\hline $\begin{array}{l}\text { Horizontal Pupil Diameter } \mathbf{( m m )} \\
\text { Mean } \pm \text { SD }\end{array}$ & $\begin{array}{c}\text { Nepafenac } \\
(\mathbf{n}=\mathbf{8 0})\end{array}$ & $\begin{array}{c}\text { Flurbiprofen } \\
(\mathbf{n}=\mathbf{8 0})\end{array}$ & P value* & MD (95\% Cl) \\
\hline At start of surgery & $8.55 \pm 0.47$ & $8.45 \pm 0.38$ & 0.28 & $0.1(-0.03$ to 0.23$)$ \\
After emulsification of nucleus & $8.09 \pm 0.55$ & $7.23 \pm 0.60$ & $<0.05^{*}$ & $0.86(0.68$ to 1.04$)$ \\
At end of surgery & $7.70 \pm 0.53$ & $6.46 \pm 0.70$ & $<0.05^{*}$ & $1.24(1.05$ to 1.43$)$ \\
Total reduction in pupillary diameter & $0.85 \pm 0.48$ & $1.98 \pm 0.68$ & $<0.05^{*}$ & $-1.13(-1.13$ to 0.95$)$ \\
Percentage total loss & 9.94 & 23.43 & $<0.05^{*}$ & - \\
\hline
\end{tabular}

Note: $\mathrm{P}<0.05$ considered statistically significant*.

Abbreviations: $\mathrm{Cl}$, confidence interval; $\mathrm{MD}$, mean difference; $\mathrm{mm}$, millimetres; $\mathrm{SD}$, standard deviation.

\section{Discussion}

In the present study, topical Nepafenac $(0.1 \%)$ proved to be more efficacious in maintaining intra-operative mydriasis during phacoemulsification surgery as compared to topical Flurbiprofen $(0.03 \%)$. The most probable reason for this might be the pro-drug nature of Nepafenac which readily diffuses into the anterior chamber, being neutral in character. It then gets hydrolysed into its active metabolite, amfenac, by hydrolases concentrated more in intraocular vascular tissues especially, retina and choroid. This not only enables a targeted delivery of the drug but also curtails its toxicity to the cornea. Also, the mean phacoemulsification time in the Nepafenac group was significantly less as compared to that of the Flurbiprofen group $(\mathrm{P}<0.05)$. This could probably be due to sustained maintenance of intra-operative mydriasis in the Nepafenac group, which allowed the surgeon better visibility of the rhexis margin

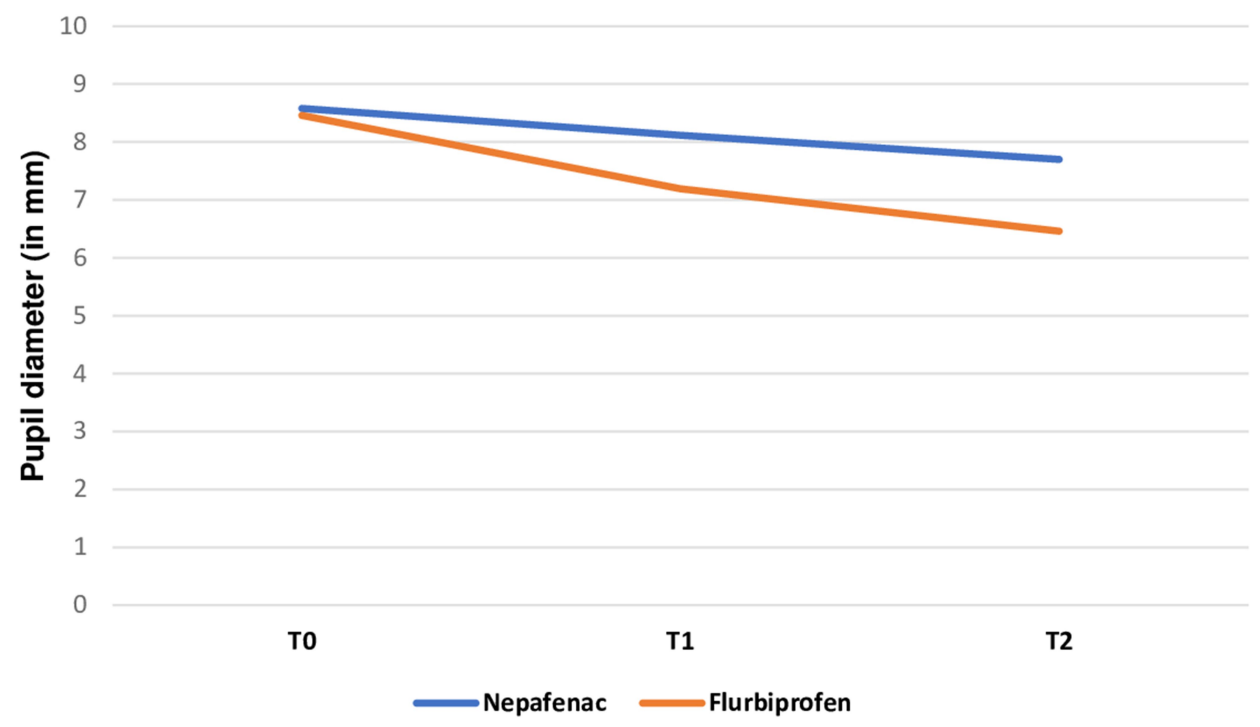

Figure 2 Comparison of pupil diameter between nepafenac and flurbiprofen group measured at three instances T0: at start of surgery, TI: after emulsification of nucleus, T2: at end of surgery. 


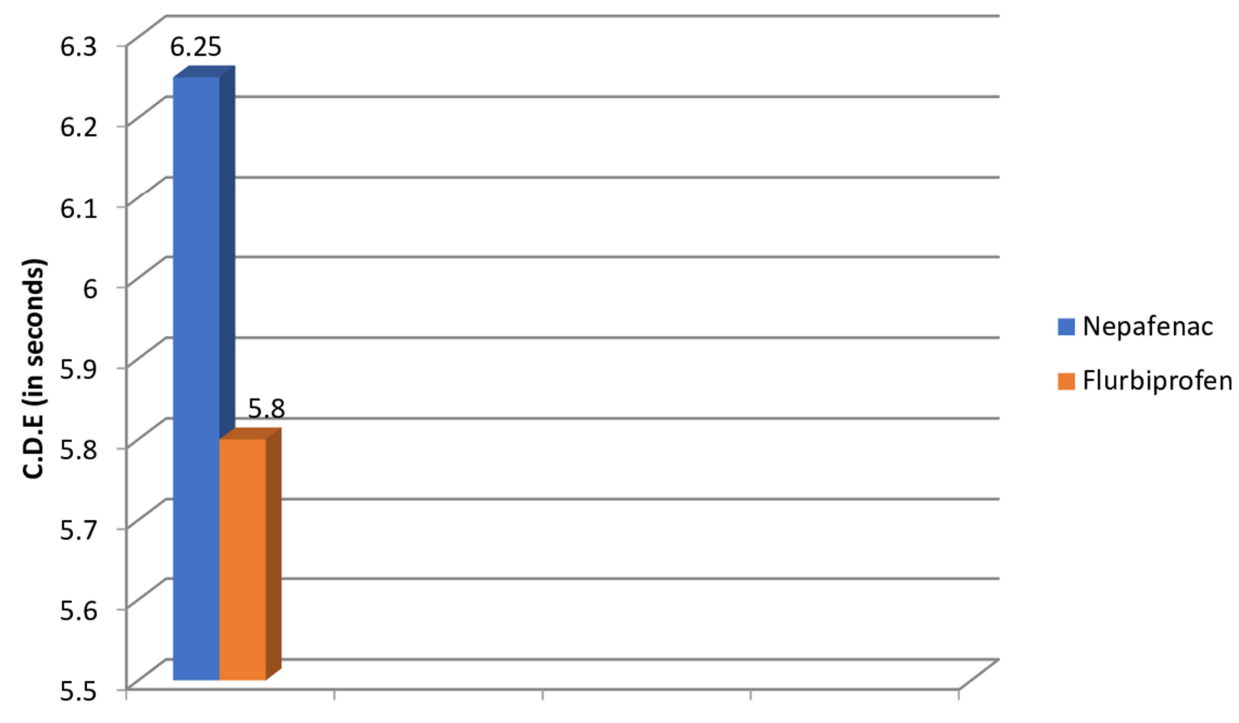

Figure 3 Comparison of mean CDE between nepafenac and flurbiprofen group. Abbreviation: $\mathrm{CDE}$, cumulative dissipated energy.

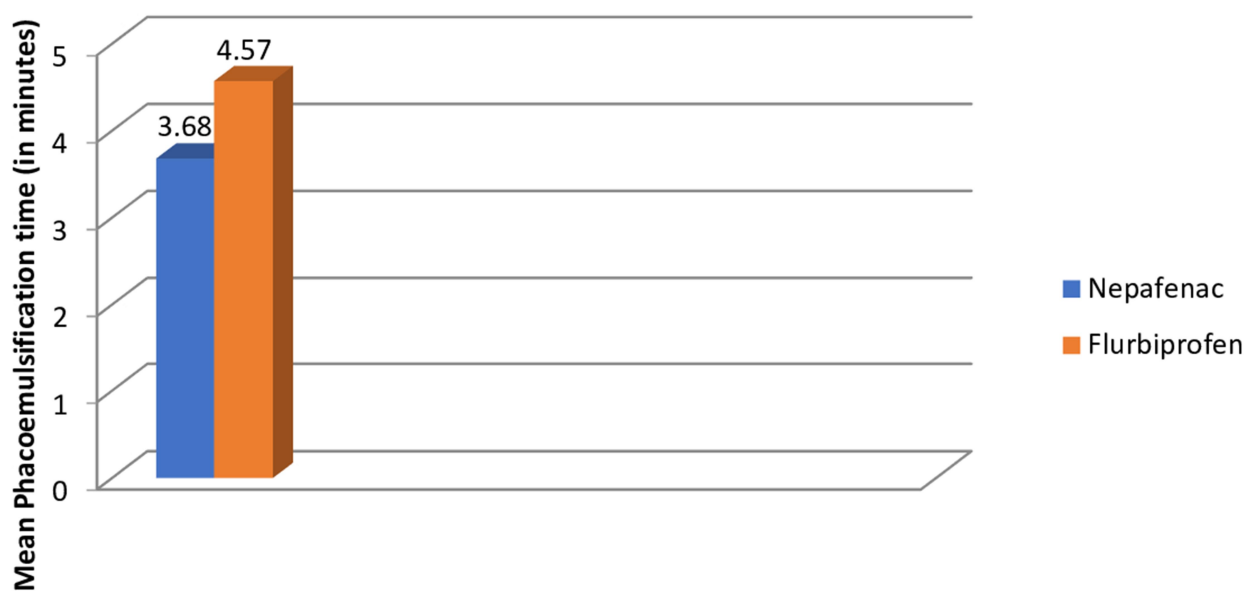

Figure 4 Comparison of mean phacoemulsification time between nepafenac and flurbiprofen group.

and posterior chamber structures. As far as CDE is concerned, there was no significant difference between the two groups $(\mathrm{P}>0.05)$ which might be due to the same ultrasound settings and surgical technique of the operating surgeon.

Several studies in the past have compared the efficacy of topical NSAIDs with placebo, corticosteroids or with other NSAIDs. In a study done by Sharma et al they were found to be superior to corticosteroids in maintaining intraoperative mydriasis and having a more prolonged effect. ${ }^{17}$ Also they have the added advantage of having lesser effect on intraocular pressure and lower risk of opportunistic infections as compared to corticosteroids. Cervantes et al in a study on 60 patients undergoing phacoemulsification revealed that the Nepafenac $(0.1 \%)$ group consistently had a greater pupillary diameter as compared to placebo, during different stages of surgery. ${ }^{18}$ Zanetti et al showed that while both NSAIDs \{Nepafenac $(0.1 \%)$ and Ketorolac $(0.4 \%)$ \} were more effective in maintaining intra-operative mydriasis as compared to placebo, there was no statistical difference amongst themselves. ${ }^{19}$ Contrary to this, Nepafenac $(0.1 \%)$ proved to be a more effective inhibitor of miosis during phacoemulsification when compared with Ketorolac $(0.5 \%)$ as shown in a study by Atanis et al. ${ }^{20}$ Gimbel et al, however, have compared a different set of NSAIDs \{Flurbiprofen $(0.03 \%)$ with Indomethacin $(1 \%)$ \} proving both to be equally efficacious in preventing miosis during phacoemulsification. ${ }^{21}$ 
Previously, three randomized control trials comparing the efficacy of topical Nepafenac $(0.1 \%)$ with Flurbiprofen $(0.03 \%)$ in maintaining intra-operative mydriasis have been reported from the Indian sub-continent. While Prakash et al studied the efficacy of these two drugs in extra capsular cataract extraction both Sarkar et al and Pradeep et al compared their effect in small incision cataract surgery (SICS). ${ }^{16,22,23}$ Both these surgical procedures, as compared to phacoemulsification, involve more handling of iris tissue and thus increased incidence of intraoperative miosis. Also as phacoemulsification is the preferred surgical procedure presently, this study was undertaken to compare the efficacy of topical Nepafenac $(0.1 \%)$ with Flurbiprofen $(0.03 \%)$ in maintaining intraoperative mydriasis during this procedure.

Sarkar et al in their study administered topical NSAIDs one day preoperatively and evaluated both vertical and horizontal pupillary diameter. ${ }^{16}$ In concordance with their results our study also shows no significant difference in pupillary diameter (both vertical and horizontal) at the start of surgery, indicating that administering NSAIDs one day prior gives no added advantage over starting them on the same day of surgery. In contrast to Prakash et al the results of Pradeep et al, Sarkar et al and our study concluded that Nepafenac was more efficacious at the end of surgery. ${ }^{16,22,23}$ This could probably be due to inclusion of diabetic patients in the study by Prakash et al. In patients with diabetes mellitus, the breakdown of blood retinal barrier results in higher concentration of TNF- $\alpha$ in the retina. ${ }^{22}$ Flurbiprofen acts by inhibiting TNF- $\alpha$ thus augmenting its effect. Another point of concern is measurement of only horizontal pupillary diameter by Prakash et al in contrast to measurement of both vertical and horizontal pupillary diameter in the other three studies. ${ }^{22}$ As explained by Rushforth et al, with narrowing of palpebral fissure, the vertical width of drug reservoir in contact with cornea decreases. ${ }^{24}$ The increased drug concentration, thus, along the horizontal meridian explains greater horizontal mydriasis over vertical mydriasis. So in an ideal situation, both vertical and horizontal pupillary diameter needs to be reported.

In contrast to topical agents intracameral mydriatics have gained popularity in the recent past. Since their introduction in 2003, they have been shown to provide adequate pupil dilatation during phacoemulsification without causing substantial ocular side-effects. ${ }^{25}$ To circumvent issues of dilution errors and incidence of toxic anterior segment syndrome (attributable to accidental use of medications containing preservatives in homemade cocktails) FDA approved preparations like Mydrane (Tropicamide $0.02 \%+$ Phenylephrine $0.31 \%+$ Lidocaine $1.0 \%$ ) and Omidria (Phenylephrine 1\% + Ketorolac 0.3\%) were instituted lately. ${ }^{26}$ Omidria needs to be stored between 20 and 25 degrees Celsius and protected from ambient light at all times prior to use. ${ }^{27}$ One $4 \mathrm{~mL}$ singlepatient-use-vial of Omidria added to $500 \mathrm{~mL}$ of irrigation solution can be delivered intracamerally within a four hour recommended time frame. ${ }^{27}$ However, these preparations are still not licensed in all countries and their global acceptance solely depends on disease burden and the economics of each country. ${ }^{26}$ In developing countries like India, where the burden of cataract surgery is enormous as compared to available resources, topical NSAIDs are still being widely used. This not only serves the purpose of maintaining intraoperative mydriasis but also the same drug can be used postoperatively for its other recognised advantages such as management of post-operative inflammation, alleviation of pain, discomfort and prevention as well as treatment of cystoid macular oedema. Besides, storage and formulation is not an issue with topical preparations as with intracameral drugs. Moreover, the use of topical formulations is a better choice in high volume centres where trainee surgeons perform the bulk of surgery and need a well dilated pupil preoperatively. Taking the financial issues into consideration, in our scenario, intracameral mydriatics can be reserved for use in cases of premium IOL implantation and in more complicated cases like poorly dilating pupils, pseudo-exfoliation and patients with intraoperative floppy iris syndrome.

The strength of our study lies in its robust study design which is a prospective, randomised, double-blind study. This increases accuracy, eliminates recall, sampling and selection bias. Moreover, all the surgeries and measurements were performed by a single surgeon using the same techniques under similar conditions, thus, preventing any probable confounding factor. Our study had few limitations. We excluded diabetic and hypertensive patients whose number is on the rise these days. Complicated cases like pseudo-exfoliation and pupil abnormalities were excluded from the study. Moreover, it was a single centre study which limits generalizability of the study results.

Thus to conclude, considering its potency in maintaining intraoperative mydriasis and other postoperative uses, we recommend topical Nepafenac $(0.1 \%)$ as a potential choice to maintain intraoperative mydriasis during routine 
phacoemulsification cataract surgery. Further studies are required comparing it with other more commonly used drugs.

\section{Funding}

There is no funding to report.

\section{Disclosure}

The authors report no conflicts of interest for this work.

\section{References}

1. Linebarger EJ, Hardten DR, Shah GK, Lindstrom RL. Phacoemulsification and modern cataract surgery. Surv Ophthalmol. 1999;44(2):123-147.

2. Gogate PM, Kulkarni SR, Krishnaiah S, et al. Safety and efficacy of phacoemulsification compared with manual small-incision cataract surgery by a randomized controlled clinical trial: six-week results. Ophthalmology. 2005;112(5):869-874. doi:10.1016/j.ophtha.2004.11. 055

3. Riaz Y, Mehta JS, Wormald R, et al. Surgical interventions for age-related cataract. Cochrane Database Syst Rev. 2006;(4): CD001323. doi:10.1002/14651858.CD001323.pub2

4. Guzek JP, Holm M, Cotter JB, et al. Risk factors for intraoperative complications in 1000 extracapsular cataract cases. Ophthalmology. 1987;94(5):461-466. doi:10.1016/S0161-6420(87)33424-4

5. Cataract surgery in small pupils: choosing the appropriate tool (Internet). CRSTEurope; 2019. Available from: https://crstodayeu rope.com/articles/2013-sep/cataract-surgery-in-small-pupils-onlinesurvey-choosing-the-appropriate-tool. Accessed February 26, 2021.

6. Hashemi H, Seyedian MA, Mohammadpour M. Small pupil and cataract surgery. Curr Opin Ophthalmol. 2015;26(1):3-9. doi:10.10 97/ICU.0000000000000116

7. Lawuyi LE, Gurbaxani A. The clinical utility of new combination phenylephrine/ketorolac injection in cataract surgery. Clin Ophthalmol. 2015;9:1249-1254. doi:10.2147/OPTH.S72321

8. Mirza SA, Alexandridou A, Marshall T, Stavrou P. Surgically induced miosis during phacoemulsification in patients with diabetes mellitus. Eye. 2003;17(2):194-199. doi:10.1038/sj.eye.6700268

9. Narendran N, Jaycock P, Johnston RL, et al. The Cataract National Dataset electronic multicentre audit of 55,567 operations: risk stratification for posterior capsule rupture and vitreous loss. Eye. 2009;23 (1):31-37. doi:10.1038/sj.eye.6703049

10. Papa V, Russo S, Russo P, et al. Topical naproxen sodium for inhibition of miosis during cataract surgery. Prospective, randomized clinical trials. Eye. 2002;16(3):292-296. doi:10.1038/sj.eye.6700124

11. Ambache N, Kavanagh L, Whiting J. Effect of mechanical stimulation on rabbits' eyes: release of active substance in anterior chamber perfusates. J Physiol. 1965;176(3):378-408. doi:10.1113/jphysiol.19 65.sp007557

12. Miyake K, Sugiyama S, Norimatsu I, Ozawa T. Prevention of cystoid macular edema after lens extraction by topical indomethacin (III) radioimmunoassay measurement of prostaglandins in the aqueous during and after lens extraction procedures. Albrecht von Graefes Arch Klin Exp Ophthalmol. 1978;209(2):83-88. doi:10.1007/ BF00407841

13. Donnenfeld ED. Current use of non-steroidal anti-inflammatory drugs in the treatment of ocular inflammation related to cataract surgery. Eur Ophthal Rev. 2012;6(3):173-177. doi:10.17925/EOR.2012.06. 03.173
14. Donnenfeld ED, Perry HD, Wittpenn JR, Solomon R, Nattis A, Chou T. Preoperative ketorolac tromethamine $0.4 \%$ in phacoemulsification outcomes: pharmacokinetic-response curve. $J$ Cataract Refract Surg. 2006;32(9):1474-1482. doi:10.1016/j.jcrs.2006.04.009

15. Moher D, Hopewell S, Schulz KF, et al; Consolidated Standards of Reporting Trials Group. CONSORT 2010 explanation and elaboration: updated guidelines for reporting parallel group randomised trials. J Clin Epidemiol. 2010;63(8):e1-e37.

16. Sarkar S, Mondal KK, Roy SS, Gayen S, Ghosh A, De RR. Comparison of preoperative nepafenac $(0.1 \%)$ and flurbiprofen $(0.03 \%)$ eye drops in maintaining mydriasis during small incision cataract surgery in patients with senile cataract: a randomized, double-blind study. Indian J Pharmacol. 2015;47(5):491-495. doi:10.4103/0253-7613.165201

17. Sharma AK, Sharma HR, Sharma R, Singh A. Comparison of preoperative topical dexamethasone phosphate versus ketorolac tromethamine in maintaining intraoperative mydriasis during small incision cataract surgery. J Clin Diagn Res. 2016;10(5):NC09NC13. doi:10.7860/JCDR/2016/19590.7863

18. Cervantes-Coste G, Sanchez-Castro YG, Orozco-Carroll M, Mendoza-Schuster E, Velasco-Barona C. Inhibition of surgically induced miosis and prevention of postoperative macular edema with nepafenac. Clin Ophthalmol. 2009;3:219-226. doi:10.2147/OPTH. S4820

19. Zanetti FR, Fulco EAM, Chaves FRP, da Costa Pinto AP, Arieta CEL, Lira RPC. Effect of preoperative use of topical prednisolone acetate, ketorolac tromethamine, nepafenac and placebo, on the maintenance of intraoperative mydriasis during cataract surgery: a randomized trial. Indian $J$ Ophthalmol. 2012;60(4):277-281. doi:10.4103/0301-4738.98705

20. Atanis R, Tuaño PM, Vicencio J, Martinez JM, Verzosa L. Effect of topical ketorolac tromethamine and topical nepafenac on maintaining pupillary dilation during phacoemulsification. Philipp J Ophthalmol. 2011;36(1):23-27.

21. Gimbel H, Van Westenbrugge J, Cheetham JK, DeGryse R, Garcia CG. Intraocular availability and pupillary effect of flurbiprofen and indomethacin during cataract surgery. $J$ Cataract Refract Surg. 1996;22(4):474-479. doi:10.1016/S0886-3350(96)80045-9

22. Prakash S, Bhandare B, Satyanarayana V, Kumar K. A comparative study on efficacy of nepafenac and flurbiprofen in maintenance of intraoperative mydriasis during cataract surgery: an open label randomized controlled trial. Int J Basic Clin Pharmacol. 2018;7 (4):617-621. doi:10.18203/2319-2003.ijbcp20181002

23. Pradeep P, Samuel. TRR. Effect of preoperative use of nepafenac and flurbiprofen eye drops in maintaining mydriasis during small incision cataract surgery. IOSR J Dental Med Sci. 2019;18(2):26-33.

24. Rushforth RL, White RL, Solum KR, Laukkanen HV. The effect of illumination on the time to and pupil area of maximum mydriasis. Canadian J Optometry. 1996;58(3):117-122.

25. Grob SR, Gonzalez-Gonzalez LA, Daly MK. Management of mydriasis and pain in cataract and intraocular lens surgery: review of current medications and future directions. Clin Ophthalmol. 2014;8:1281-1289. doi:10.2147/OPTH.S47569

26. Srinivasan S. Intracameral mydriatics during cataract surgery. $J$ Cataract Refract Surg. 2018;44(3):257-258. doi:10.1016/j.jcrs.20 18.03.007

27. Rosenberg ED, Nattis AS, Alevi D, et al. Visual outcomes, efficacy and surgical complications associated with intracameral phenylephrine $1.0 \%$ /ketorolac $0.3 \%$ administered during cataract surgery. Clin Ophthalmol. 2018;12:21-28. doi:10.2147/OPTH.S149581 


\section{Publish your work in this journal}

Clinical Ophthalmology is an international, peer-reviewed journal covering all subspecialties within ophthalmology. Key topics include: Optometry; Visual science; Pharmacology and drug therapy in eye diseases; Basic Sciences; Primary and Secondary eye care; Patient Safety and Quality of Care Improvements. This journal is indexed on PubMed
Central and CAS, and is the official journal of The Society of Clinical Ophthalmology (SCO). The manuscript management system is completely online and includes a very quick and fair peer-review system, which is all easy to use. Visit http://www.dovepress.com/ testimonials.php to read real quotes from published authors.

Submit your manuscript here: https://www.dovepress.com/clinical-ophthalmology-journal 